\title{
Transient Voltage Analysis for Dynamic Positioning Closed Bus Electrical System on Ship in Laboratory Scale
}

\author{
Sardono Sarwito ${ }^{1}$, Eddy Setyo Koenhardono ${ }^{2}$, A. A. Masroeri ${ }^{3}$, Indra Ranu Kusuma ${ }^{4}$, Mochamad Nur \\ Ichwan $^{5}$
}

(Received: 02 August 2019 / Revised: 10 September 2019/ Accepted: 30 September 2019)

\begin{abstract}
- ships equipped with a dynamic positioning system have more number of thuster than ships that are not equipped with a dynamic positioning system. The addition of this thruster resulted in a significant increase in electrical loads so that the power plant will be added to the vessel. Dynamic positioning is a system used to support offshore vessel work consisting of a collection of equipment and control systems that work simultaneously to maintain the position of a vessel in accordance with which has been input into the system. Installation of the dynamic positioning system on the vessel affects the electrical system of the vessel. In the operation of electrical system on the vessel found the disturbances that arise one of them is transient interference that causes the change of voltage and frequency value in a short time. A Transient voltage occurs within a few seconds where the system conditions are unstable. The research was conducted in a laboratory scale by modeled a series of vessels that have the system with existing laboratory equipment where transient interference occurred due to the starting motor so that it is done Analysis of the magnitude of the voltage and frequency in the specified scenario as well as finding a solution to correct emerging interference that exceeds the standard. In the experiments made some configuration changes and obtained the result that the configuration of Split Plant 1 generator thruster has good system stability capable of achieving a stable condition with a loading of $50 \%$. As for the loading of $60 \%$ stability of the system is unstable and can be improved again with the addition of capacitor.
\end{abstract}

Keywords—dynamic positioning system, transient voltage

\section{INTRODUCTION}

G ood vessel electrical system can optimize ship's operational performance. The system consists of generating systems, distribution systems, and electrical loads. The design of the ship's electrical installation must be based on terms or conditions applicable to the system on board [1-3]. In addition to the selection of generators that fit the needs must pass several stages until finally found the type of machine suitable to be mounted on board. These stages include the required power calculations, determination of the type and size in accordance with the conditions of the space to be occupied. Electrical system planning on board should be able to maintain the continuity of existing electric power availability, so that in planning necessary considerations so that the generators used can serve the needs of electricity Various operating conditions on board. [4-5] The operating conditions of a vessel are divided into sailing conditions, maneuvering, loading and unloading, and anchoring. With the consideration of the condition of the operation, it will be obtained the optimal power supply service.

Dynamic Positioning (DP) is a system used to support the work of the offshore vessels consisting of a collection of equipment and control systems that work

Sardono Sarwito, Department of Marine Engineering, Institut Teknologi Sepuluh Nopember, Surabaya 60111, Indonesia, Email: sardonosarwito@gmail.com

Eddy Setyo Koenhardono, Department of Marine Engineering, Institut Teknologi Sepuluh Nopember, Surabaya 60111, Indonesia, Email: koenhardono@gmail.com

A. A Masroeri, Department of Marine Engineering, Institut Teknologi Sepuluh Nopember, Surabaya 60111, Indonesia, Email: masroeri@its.ac.id simultaneously to maintain the position of a vessel in accordance with the Ordinance Input into the system. Installation of the dynamic positioning system on the vessel affects the electrical system of the vessel. Installation of components certainly added loads that must be supplied by electric power, so it also affects the selection of power plants on the vessel. A power station on board should be able to supply the entire load on the ship continuously so that the selection of generators and system configurations must be strictly noted. DP system in general consists of power system, thruster system, and control system [6].

With the technology in the field of shipping, especially in the field of dynamic positioning system, the vessel electrical system uses open bus configurations that are varied into a split plant to support redundancy in the system. The closed bus configuration allows the system to maximize the efficiency of generator usage because its operation approaches the total load. While the split plant configuration allows the system to be able to isolate failures only on one part of the system. The use of split plant configuration turned out to produce more emissions so that some Parties consider using closed bus configurations on ships equipped with a dynamic positioning system [7-8].

In fact the conditions in the field are erratic according to the environmental factors involved can

Indra Ranu Kusuma, Department of Marine Engineering, Institu Teknologi Sepuluh Nopember, Surabaya 60111, Indonesia, Email: irkusuma97@gmail.com

Mochamad Nur Ichwan, Department of Marine Engineering, Institut Teknologi Sepuluh Nopember, Surabaya 60111, Indonesia, Email: ichwanmn@gmail.com 
cause a system to experience interference. An electrical system is vulnerable to interference so that a system must have the ability to maintain its synchronous state, this capability is called transient stability.

It occurs when there is an overload in one of the generators, starting on the motor, and also a brief connection to the components that usually occur on vessels equipped with a dynamic positioning system. In this research will be conducted a transient analysis of the voltage on the vessel dynamic positioning in a closed circuit based on the laboratory scale in each configuration to be done [9-11].

A. Ship Electrical System with Dynamic Positioning Vessels that are equipped with DP system have more thuster number than ship that is not equipped with DP system. The addition of this thruster resulted in a significant increase in electrical loads so that the power plant will be added to the vessel.

The classification of the DP system distinguishes the system into 3 classes, one of its requirements is in terms of system redundancy. This difference resulted in a different configuration on the electric power system in the vessel equipped with the DP system to minimize the risk of system failure due to interference in the power system.

Generally the ship has an electrical system with closed bus configurations, a configuration that can put all the buses in a connected state. The meaning is the electrical system that permits one and more plants to supply all the loads on the ship. To maximize fault tolerance in DP systems, electrical systems are generally designed separately (islanded) to reduce the likelihood of disruption of the system due to one fault. Unlike systems designed using closed buses, designing using an open bus will only impact on the affected bus, effectively isolating the problem in the affected areas only. The goal is to avoid system failures due to one fault where the entire system can experience blackout by isolating failures on only one redundancy system [12-13].
B. Transient Stability

Transient stability is the ability of the power system to maintain synchronous conditions when transient interference is a major disruption that occurs suddenly in the power system. Under normal conditions an electrical system should be able to get a balance between the mechanical power of the prime mover with the power output to load on the system. Additional or reduced load on the system should be followed by the change of mechanical power input of the prime mover on the generator. If mechanical input power cannot follow the system load changes, the rotor speed generator, system frequency and voltage will deviate from the sync state [14-15].

In the meantime, there is an imbalance between the prime mover input power and if it is not addressed, the system will experience missing synchronization. Based on its nature, disruption to the stability of the listic system is divided into 3 categories:

1. Fixed stability (steady state)

2. Transient stability

3. Sub-switching stability (dynamic)

Steady state stability is the ability of electric power systems to maintain synchronous state after experiencing small-scale load fluctuations. Switching stability is the ability of the electric power system to maintain synchronous conditions after experiencing sudden major disruption of one swing or one swing assuming that the automatic voltage regulator (AVR) has not worked. The stability of sub-switching is when after the first swing in the system transient stability period can maintain the synchronous state until the system returns to a balanced state according to the prevailing rules [16].

\section{IEEE Standard}

\section{Frequency Standar}

According to the IEEE standard 106-2003 generator ability to withstand the under/over frequency phenomenon described in the following 2 figure :

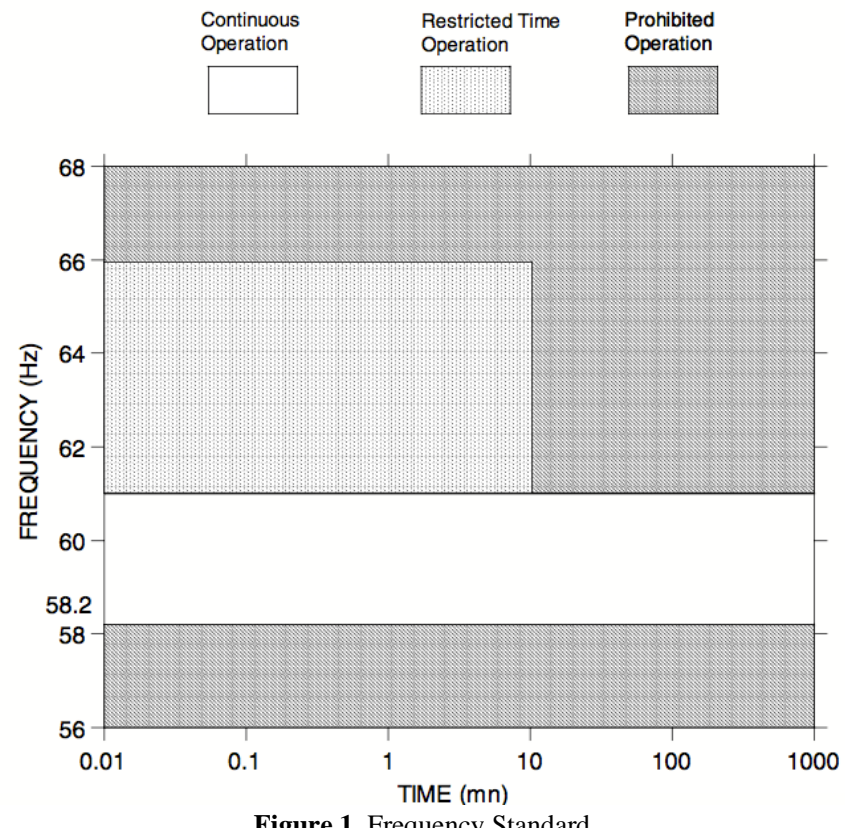

Figure 1. Frequency Standard 
From the above image can be taken explanation as follows:

-Under frequency allowed up to $58.2 \mathrm{~Hz}$

-Over frequency allowed up to $61 \mathrm{~Hz}$

For systems with a frequency of $50 \mathrm{~Hz}$, it is necessary to change the unit to form $\%$ for the data to be found. Then for frequencies $50 \mathrm{~Hz}$,

$-(58.2 / 60) \times 100 \%=97 \%$
$-(61 / 60) \times 100 \%=101.67 \%$

Then the frequency is expected not to touch the value above when steady state to maintain system stability.

\section{Voltage Standard}

According to IEEE standard 1195, transient interference that can occur are voltage dip, voltage swell, over voltage and under voltage. The standard of voltage flicker can be seen in the following figure:

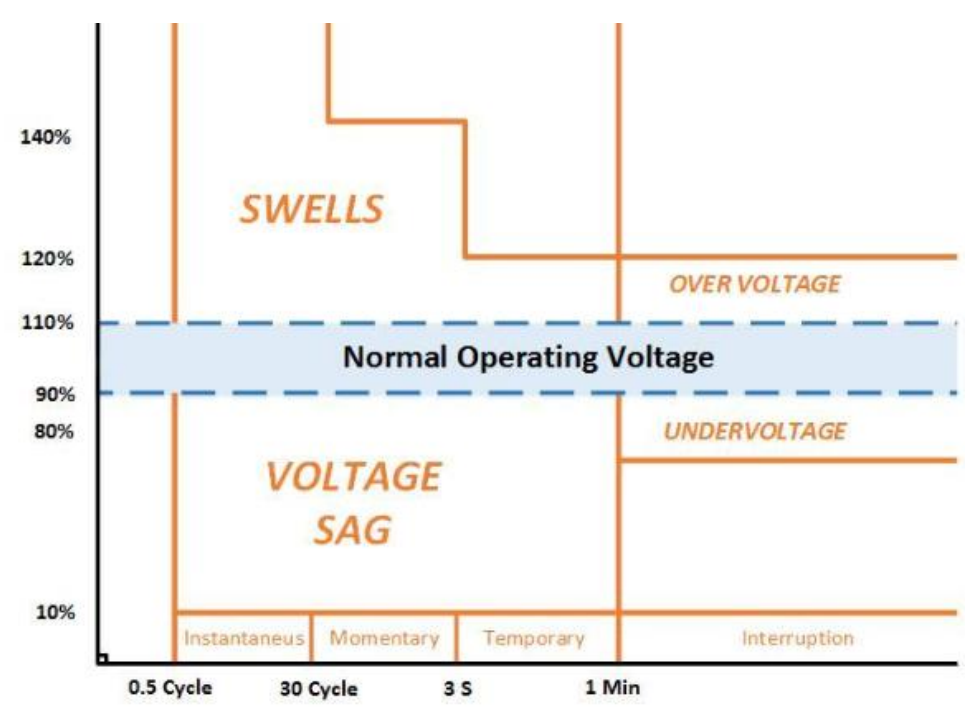

Figure 1. Standard operating voltage limits of transient stability

From the above image can be taken some explanation as follows:

- Normal operating voltage range $90 \%-110 \%$ of the nominal voltage.

- The voltage of the SAG/dip is a voltage drop that is temporarily up to a range of $10 \%-90 \%$ nominal voltage.

- The voltage swells is a rising voltage that is temporarily up to the range of $110 \%-180 \%$ of the nominal voltage.

- The duration of the voltage dip is divided into 3 categories that are instantaneous $(0.5$ cycle -30 cycle $)$, Momentary (30 Cycle $-3 \mathrm{sec}$ ), and temporary (3 seconds $-1 \mathrm{~min})$.

- Undervoltage and overvoltage including category sustained interruption

\section{METHOD}

Before conducting laboratory scale experiments, a single line from the electrical system of the dynamic positioning vessel is required. Referring to the single line diagram, the system will be depicted in the series according to the equipment in the laboratory. The results obtained from the experiment are the data in the form of voltage and frequency per unit of time, where the value can be searched from the waveform of the oscilloscope. This Data will then be processed and analyzed so that the transient voltage assessment and system stability can be performed. The system will then be set to 3 different scenarios stated in Table 1. And by performing a capacitor mounting on a variation that has impaired standards are not compliant.

TABLE 1.

SIMULATIONS SCENARIO

\begin{tabular}{|c|c|c|c|}
\hline Scenario & Power Supply & Load & Load Variations \\
\hline 1 & 2 Generator Thruster (Closed Bus) & 2 Bow Thruster & $\begin{array}{c}60 \%-75 \% \\
100 \%-80 \% \\
100 \%-100 \%\end{array}$ \\
\hline 2 & 1 Generator Thruster (Split Plant) & 2 Bow Thruster & $\begin{array}{l}40 \%-40 \% \\
50 \%-50 \% \\
60 \%-60 \%\end{array}$ \\
\hline 3 & $\begin{array}{l}1 \text { Generator Thruster, } 1 \text { Diesel } \\
\text { Generator (Closed Bus) }\end{array}$ & $\begin{array}{l}2 \text { Bow Thruster \& Ship } \\
\text { Equipment Load }\end{array}$ & $\begin{array}{l}80 \%-80 \% \\
85 \%-85 \% \\
90 \%-90 \%\end{array}$ \\
\hline
\end{tabular}




\section{RESULT AND ANALYSIS}

To get an electrical system that has high stability, there are several ways that can be done. In this study will be simulated changes in system configuration and also design scenarios with the installation of capacitors to improve system stability.

A study designed to assess the stability of a system is the bow thruster with maximum variation in a predefined configuration. The configuration scenario and variations of the bow thruster can be seen in table 2 .

The following test results are summarized as per the scenarios shown in table 3 onwards. Configuration of closed Bus 2 generator thruster to bear 2 bow thruster. The voltage and frequency response to this configuration indicates that the system can only maintain a stable condition up to $100 \%-80 \%$ on the bow thruster, while the load is $100 \%-100 \%$ unstable system conditions.

TABLE 2.

VOLTAGE AND FREQUENCY RESPONSES OF SCENARIO 1 SUMMARY

\begin{tabular}{|c|c|c|c|c|c|c|c|c|}
\hline \multirow{3}{*}{ No } & \multirow{3}{*}{ Variation } & \multirow{3}{*}{$f \min (\%)$} & \multicolumn{3}{|c|}{ Simulation 1} & \multirow{3}{*}{$\begin{array}{c}\mathrm{v} \text { when avr } \\
\text { manually }(\%)\end{array}$} & \multirow{2}{*}{\multicolumn{2}{|c|}{ Condition }} \\
\hline & & & f steady & sin $(\%)$ & v steady & & & \\
\hline & & & state $(\%)$ & $\operatorname{Vinm}(\%)$ & state $(\%)$ & & $\mathbf{f}$ & $\mathbf{v}$ \\
\hline 1 & $60 \%-75 \%$ & 99.30 & 99.30 & 79.75 & 91.14 & 98.86 & $\mathbf{v}$ & $\mathbf{v}$ \\
\hline 2 & $80 \%-100 \%$ & 99.04 & 99.04 & 77.27 & 90.80 & 98.41 & $\mathbf{v}$ & $\mathbf{v}$ \\
\hline 3 & $100 \%-100 \%$ & 98,91 & 98.91 & 70.45 & - & 97.73 & $\mathbf{v}$ & $\mathbf{x}$ \\
\hline
\end{tabular}

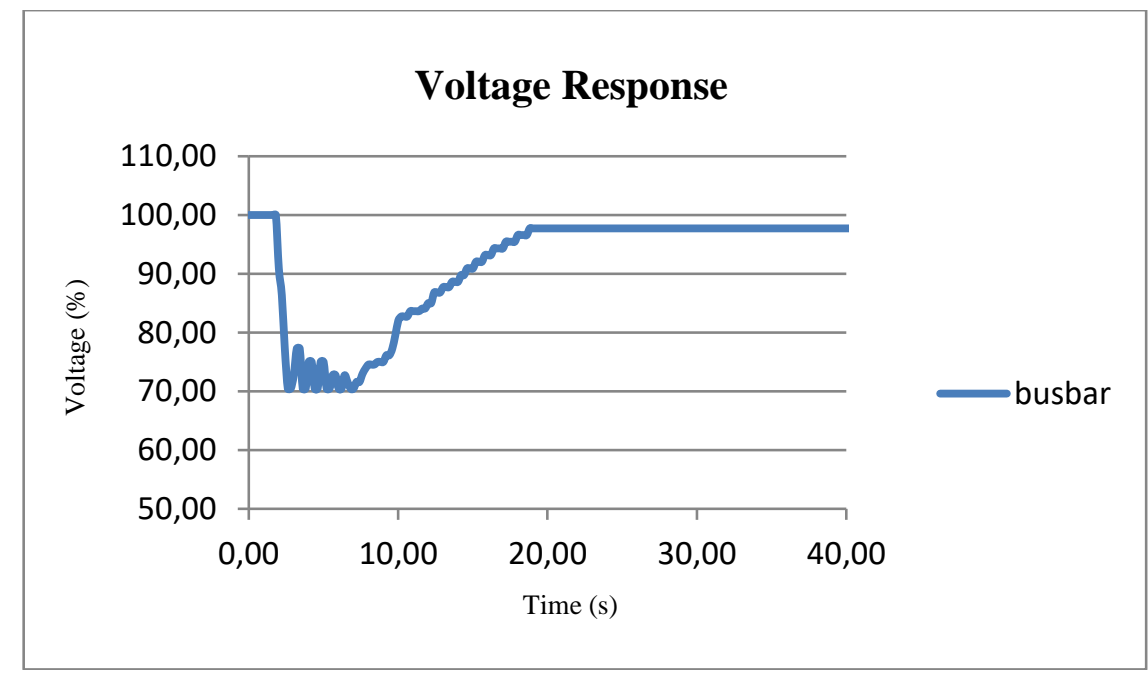

Figure 2. Voltage Response of Scenario 1 Variation 3

On the bus there is transient condition due to starting motor (bow thruster) in which the voltage generator is down 0.6 second with the lowest value of $70.45 \%$ at 2.6 seconds and then occurs up down the voltage causing the system to become unstable before Then manually raised voltage reaches a value of $97.73 \%$. In this case the oscillation occurs for several seconds before the AVR manually. 


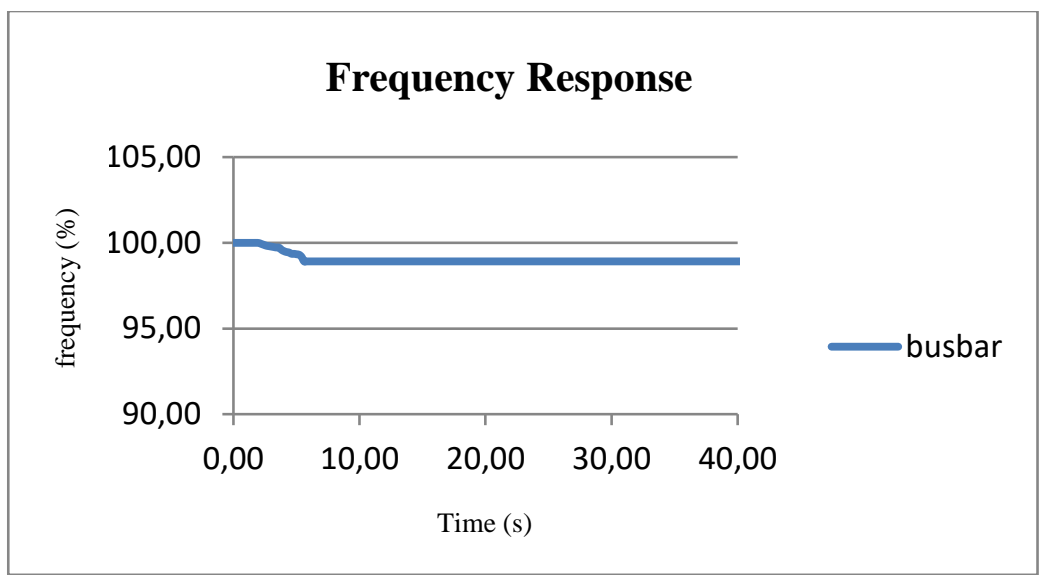

Figure 3. Frequency Response of Scenario 1 Variation 3

In the Busbar there is transient condition due to starting motor (bow thruster) where the frequency decreases to $98.91 \%$ and directly stable on the condition and value. The value is still compliant with allowed standards so the system is still allowed to operate. Configuration of the split Plant 1 generator thruster to bear 2 bow thruster drafted to achieve the goal of saving the use of generators. The voltage and frequency response to this configuration indicates that the system can only maintain its stable state until the loading of $50 \%$ in each bow thruster, while the loading of $60 \%$ of the system is unstable.

TABLE 3.

VOLTAGE AND FREQUENCY RESPONSES OF SCENARIO 2 SUMMARY

\begin{tabular}{|c|c|c|c|c|c|c|c|c|}
\hline \multirow{3}{*}{ No } & \multirow{3}{*}{ Variation } & \multirow{3}{*}{$f \min (\%)$} & \multicolumn{3}{|c|}{ Simulation 2} & \multirow{3}{*}{$\begin{array}{c}\mathbf{v} \text { when avr } \\
\text { manually }(\%)\end{array}$} & \multirow{2}{*}{\multicolumn{2}{|c|}{ Condition }} \\
\hline & & & f steady & & v steady & & & \\
\hline & & & state $(\%)$ & $\mathbf{v} \min (\%)$ & state $(\%)$ & & $\mathbf{f}$ & $\mathbf{v}$ \\
\hline 1 & $40 \%-40 \%$ & 98.78 & 98.78 & 70.45 & 90.91 & 98.86 & $\mathbf{v}$ & $\mathbf{v}$ \\
\hline 2 & $50 \%-50 \%$ & 98.02 & 98.02 & 68.18 & 90.23 & 98.75 & $\mathbf{v}$ & $\mathbf{v}$ \\
\hline 3 & $60 \%-60 \%$ & 97.01 & 97.01 & 65.91 & - & 98.18 & $\mathbf{v}$ & $\mathbf{x}$ \\
\hline
\end{tabular}

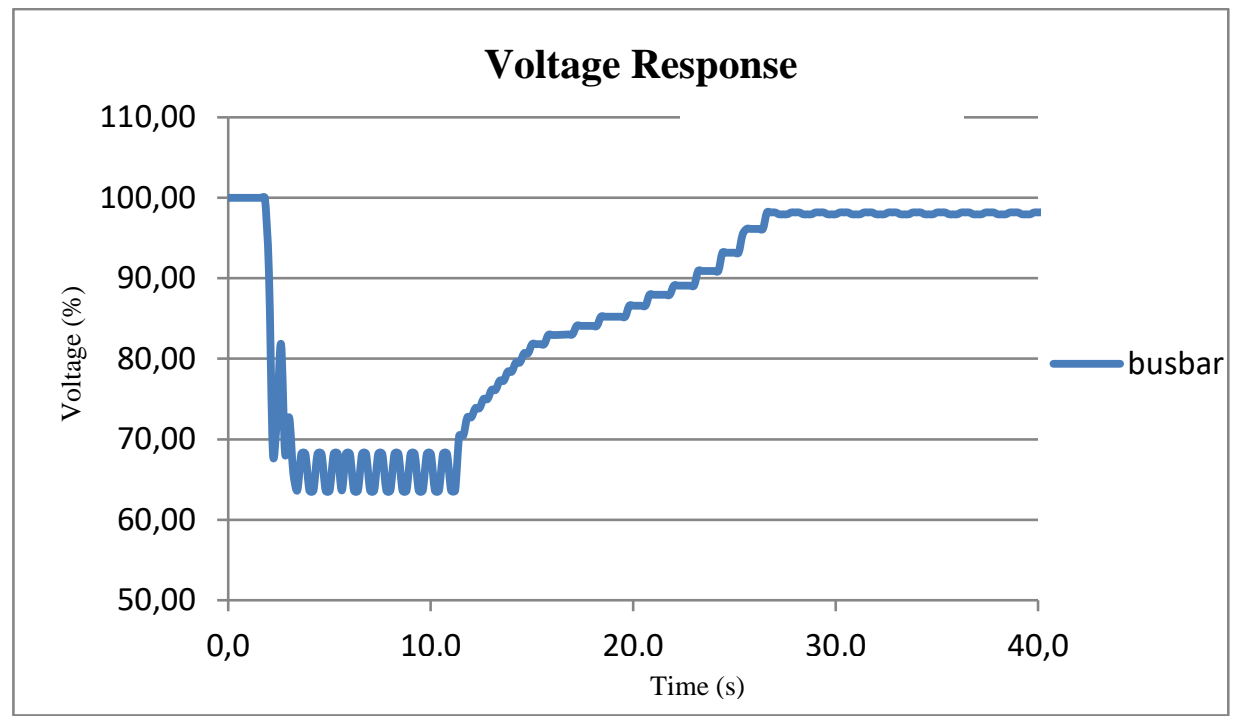

Figure 4. Voltage Response of Scenario 2 Variation 3

On the bus there is transient condition due to starting motor (bow thruster) in which the voltage generator is down 1.4 second with the lowest value of $63.64 \%$ at 3.4 seconds and then occurs up down the voltage causing the system to become unstable before Then manually raised voltage reaches a value of $98.18 \%$. In this case the oscillation occurs for a few seconds before finally in the AVR manually. 


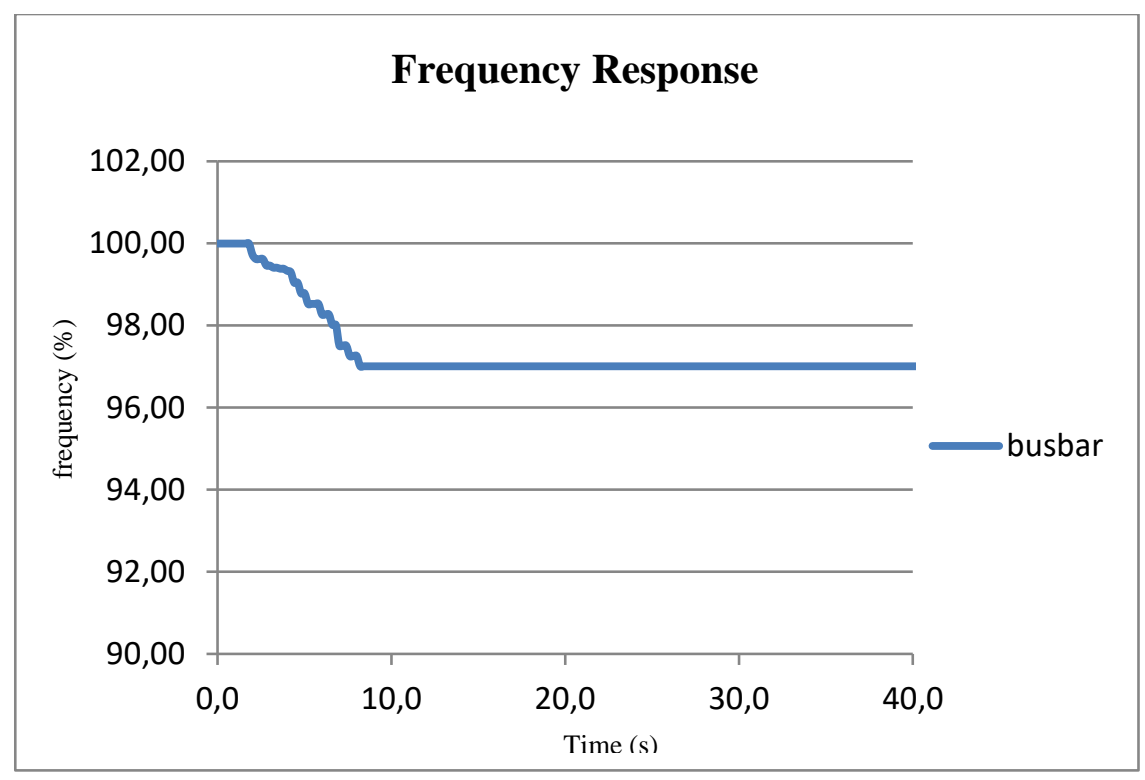

Figure 5. Frequency Response of Scenario 2 Variation 3

In the Busbar there is transient condition due to starting motor (bow thruster) where the frequency decreases to $97.01 \%$ and directly stable on the condition and value. The value is still compliant with allowed standards so the system is still allowed to operate.
Configuration of closed bus 1 generator thruster and 1 diesel generator to bear 2 bow thruster. The voltage and frequency response to this configuration indicates that the system can maintain its stable condition in all predetermined variations.

TABLE 4.

VOLTAGE AND FREQUENCY RESPONSES OF SCENARIO 6 SUMMARY

\begin{tabular}{|c|c|c|c|c|c|c|c|c|}
\hline \multirow{3}{*}{ No } & \multirow{3}{*}{ Variation } & \multirow{3}{*}{$f \min (\%)$} & \multicolumn{3}{|c|}{ Simulation 3} & \multirow{3}{*}{$\begin{array}{c}v \text { when avr } \\
\text { manually }(\%)\end{array}$} & \multirow{2}{*}{\multicolumn{2}{|c|}{ Condition }} \\
\hline & & & f steady & $\min (\theta)$ & v steady & & & \\
\hline & & & state $(\%)$ & $\mathbf{v} \min (\%)$ & state $(\%)$ & & $\mathbf{f}$ & $\mathbf{v}$ \\
\hline 1 & $75 \%-75 \%$ & 98,14 & 98,14 & 79,55 & 98,18 & 99,77 & $\mathbf{v}$ & $\mathbf{v}$ \\
\hline 2 & $80 \%-80 \%$ & 98,14 & 98,14 & 72,73 & 97,73 & 99,77 & $\mathbf{v}$ & $\mathbf{v}$ \\
\hline 3 & $85 \%-85 \%$ & 97,26 & 97,26 & 59,09 & 97,73 & 99,77 & $\mathbf{v}$ & $\mathbf{v}$ \\
\hline
\end{tabular}

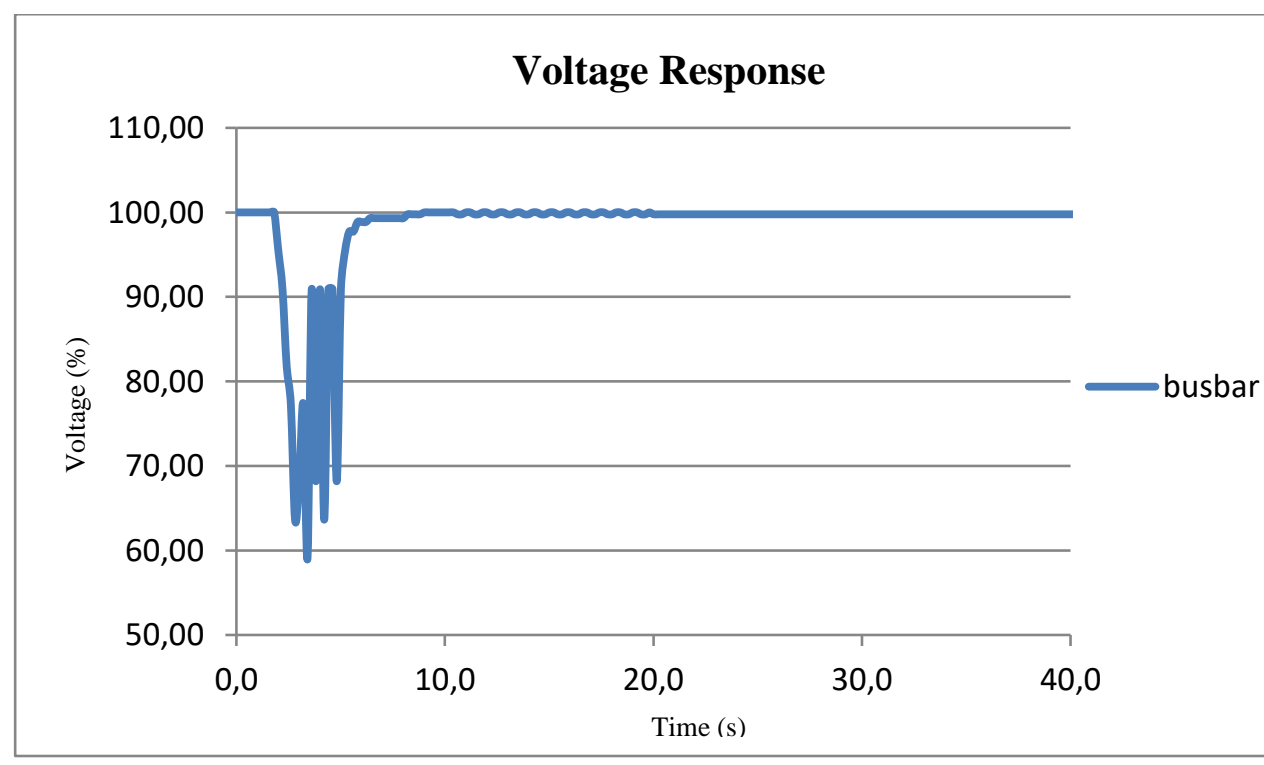

Figure 6. Voltage Response of Scenario 3 Variation 3

On the bus there is transient condition due to starting motor (bow thruster) in which the voltage generator is down 0.8 second with the lowest value $63.64 \%$ at 2.8 seconds then reach the steady state condition at the value of $97.73 \%$ before then raised manually reaches $99.77 \%$. In this case the deviation value of the voltage and the stability condition meet the standard so that the condition can be classified as stable. 


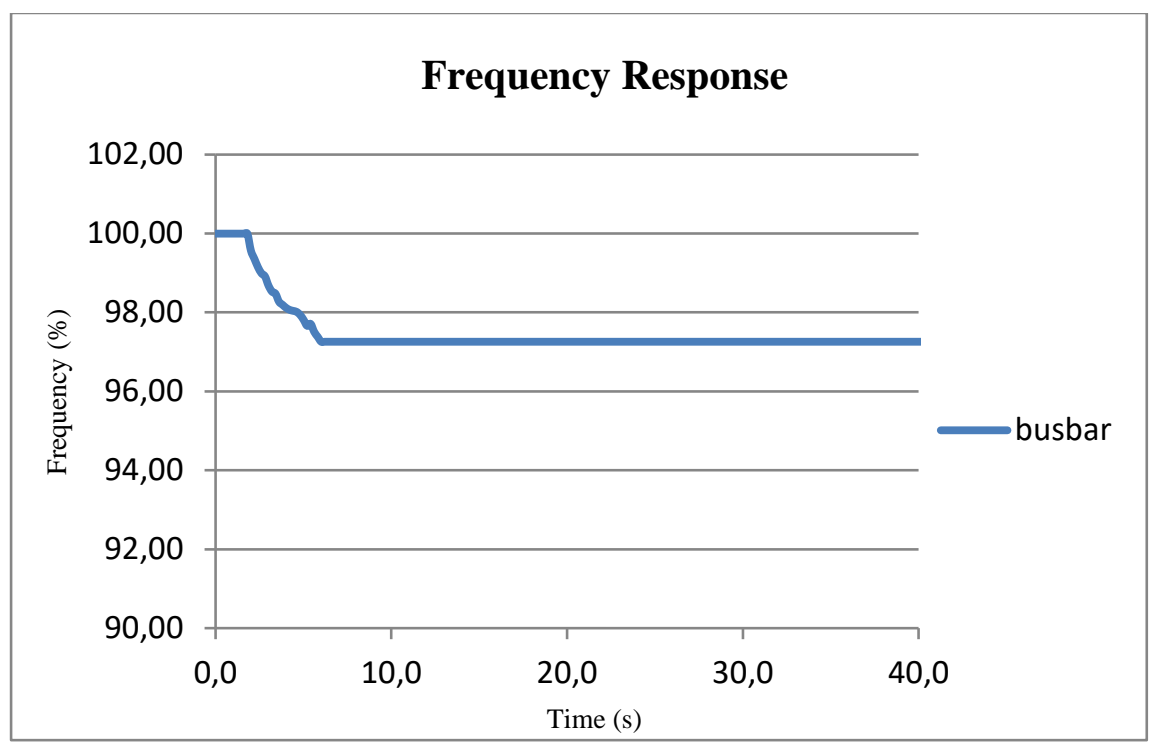

Figure 7. Frequency Response of Scenario 3 Variation 3

In the Busbar there is transient condition due to starting motor (bow thruster) where the frequency decreases to $97.26 \%$ and directly stable on the condition and value. The value is still compliant with allowed standard so the system is still allowed to operate.

After obtaining the voltage and frequency values in each variation, it is next to improve the stability of the system on the variation that occurs in the stabilization. Next displayed a comparison of the voltage response and frequency response of the system configuration that occurs oscillation when the transient conditions are in Scenario 1 Variation 3 (2 generators thruster to 2 thrusters with a load of $100 \%-100 \%)$ and Scenario 2 variation 3 (1 generator thruster for 2 thruster with load 60\%-60\%) Without capacitors and by using capacitors. The capacity of the capacitor used in this experiment is suitable in the laboratory of $14 \mu \mathrm{F}$.

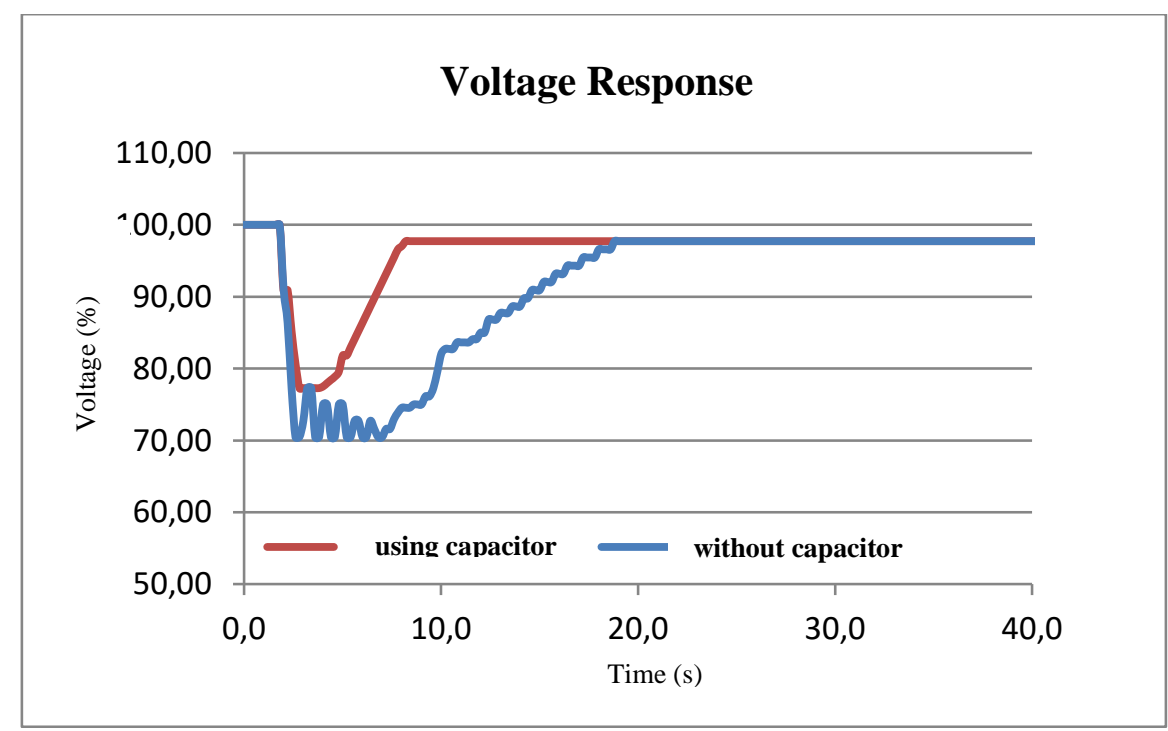

Figure 8. Comparisons of Voltage Respons With and Without Load Capasitor in 100\% Load Variations 


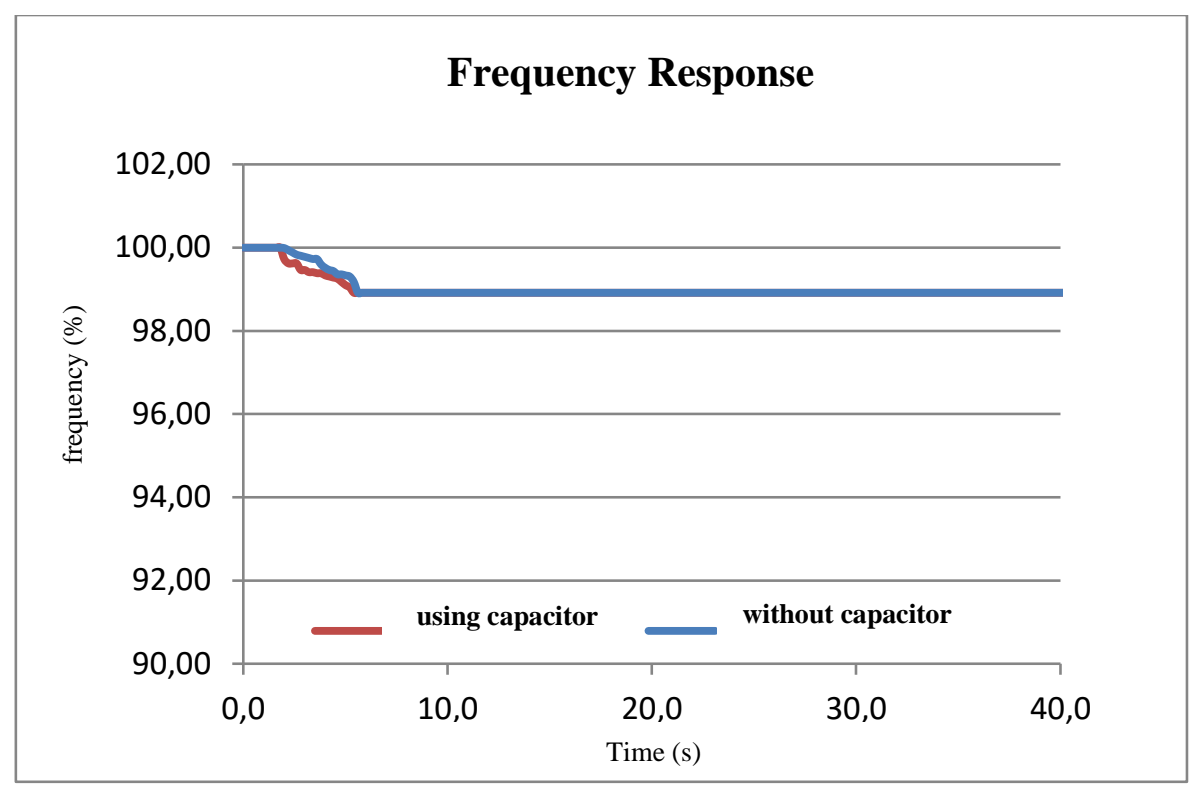

Figure 9. Comparisons of Frequency Respons With and Without Capasitor in $100 \%$ Load Variations

\section{CONCLUSION}

Based on the results of experiments that have been done can be taken several conclusions as follows:

1. Modeling electrical system Vessel dynamic Positioning System Laboratory scale obtained value to know the voltage and frequency of the system in transient conditions. For the first scenario, two thruster generators, in the first variation $(60 \%-75 \%)$ and second (100\%-80\%) Can bear the burden of 2 bow thruster, so the system is in a stable state. But on the third variation (100\%-100\%) Voltage oscillation occurs which causes the system to be unstable. For the second scenario, one thruster generator, in the first variation $(40 \%-40 \%)$ and second (50\%-50\%) Can bear the burden of 2 bow thruster, so the system is in a stable state. But on the third variation $(60 \%-60 \%)$ Voltage oscillation occurs which causes the system to be unstable. For the third scenario, one thruster generator and one diesel generator, the first variation $(75 \%-75 \%)$, the second $(80 \%-80 \%)$, and the third $(85 \%=85 \%)$ Can bear the burden of 2 bow thruster, so the system is in a stable state.

2. On the variation of loading that has oscillation is done solution to improve system stability. The solution is the installation of a capacitor on a system with a capacity of $14 \mathrm{Mf}$. From the results of the mounting capacitor obtained the value of the increased voltage from the previous, and also make the system in a stable state

\section{REFERENCES}

[1] G. Ritchie, Offshore support vessels: a practical guide, 1st. ed. London: The Nautical Inst, 2008.

[2] J. Holvik, "Basic of Dynamic Positioning," Synamic Positioning Conference, 1998.

[3] M. Roa, "Demonstration of fault ride through capability for closed bus operation on dynamic positioning vessels," 2016

[4] "Definition and Classification of Power System Stability IEEE/CIGRE Joint Task Force on Stability Terms and Definitions," IEEE Transactions on Power Systems, vol. 19, no. 3, pp. 1387-1401, Aug. 2004.
[5] P. Kundur, Power System Stability and Control. California, CA: McGraw Hill, Inc., 1994.

[6] S. Sarwito, E.S. Koenhardoni, K.P. Taradipa Analysis of Transient Response and Harmonic Disturbances on the Tanker's Electrical System Based on Simulation, 2018.

[7] S. Sarwito, M.A. Sulaiman, "Analysis Of Electric Propulsion Performance On Submersible $60 \mathrm{M}$ With Motor Dc 2x1850 Kw 380 V Using Ohmformer At Voltage 190 Vdc 10260 Ah And Without Using Ohmformer At Voltage 115 Vdc 10260 Ah, 2018.

[8] S. Sarwito, Semin, A. Suherman, "Analysis of Three Phases Asynchronous Slip Ring Motor Performance Feedback Type 243," 2017.

[9] S. Sarwito, Semin, M.B. Zaman, "Transient Stability Analysis On Ahts Vessel Electrical System Using Dynamic Positioning System, 2019.

[10] I.R. Kusuma, S. Sarwito, R.A.Widya, "Analysis of Electric Propulsion Performance on Submersible", 2017.

[11] Arbi, S., "Analysis of Voltage and Frequency Stabilitis on DG Connected AC Microgrid in Grid Connected and Islanding Modes", ITS, 2017.

[12] Asy'ari, H., "Repair Voltage Drop and Load Reconfiguration in the Prambanan Main Panel 5", 2011.

[13] Erhaneli, A.R., "Effect of Network Addition on Tegagan Drop on SUTM 20 k", 2013.

[15] Sumanto, "Electric Motors Alternating Current", Jakarta, 1995.

[14] Sutisna S, E., Mulyatno, I.P., Jokosisworo, S., "Strength Analysis of Main Deck Structure as Supporting Towing Winch on OSV Ships. Go Perseus Using the Finite Element Method", 2017

[16] Dharamjit, D.K, "Load Flow Analysis on IEEE 30 bus System", 2012. 